\title{
Relationship between achieved blood pressure, dietary habits and cardiovascular disease in hypertensive patients treated with olmesartan: the OMEGA study
}

This article has been corrected since Advance Online Publication, and a corrigendum is also printed in this issue.

\author{
Tamio Teramoto ${ }^{1}$, Ryuzo Kawamori ${ }^{2}$, Shigeru Miyazaki ${ }^{3}$, Satoshi Teramukai ${ }^{4}$, Masayuki Shirayama ${ }^{5}$, \\ Katsutoshi Hiramatsu ${ }^{5}$, Fumiaki Kobayashi ${ }^{5}$ and the OMEGA Study Group ${ }^{6}$
}

We investigated the relationship between cardiovascular disease (CVD) and the achieved blood pressure, dietary habits and the presence/absence of metabolic syndrome (MetS) in hypertensive patients treated with olmesartan medoxomil. A prospective cohort study with a 3-year follow-up was conducted in 14721 olmesartan-naive outpatients (mean age: 64.9 years, $49.6 \%$ women) with essential hypertension. The association of CVD with achieved blood pressure, dietary habits and MetS was investigated by Cox proportional hazards analysis. There were 3059 patients $(31.8 \%)$ with MetS (Japanese criteria) among 9625 evaluable patients. The mean baseline blood pressure was $157.4 / 88.8 \mathrm{~mm} \mathrm{Hg}$, which decreased to $134.0 / 76.1 \mathrm{~mm} \mathrm{Hg}$ during treatment $(P<0.0001)$. The annual incidence of CVD was 7.15 per 1000 persons during the study period. When the achieved blood pressure was stratified according to the Japanese Society of Hypertension Guidelines for the Management of Hypertension (JSH 2009), the risk of CVD increased significantly along with the severity of hypertension $(P<0.0001)$, especially the risk of stroke. Investigation of dietary habits revealed a significant association between salt intake and the risk of stroke. Higher salt intake was associated with a significantly higher risk of stroke than lower salt intake (hazard ratio, 1.897; 95\% confidence interval, 1.003-3.590). Blood pressure was well controlled in both patients with and without MetS, and there was no significant difference in the incidence of events between the two groups. In conclusion, the severity of hypertension (achieved blood pressure) is associated with the incidence of CVD, and the results of this study suggest that tight blood pressure control and salt restriction are important for preventing stroke.

Hypertension Research (2012) 35, 1136-1144; doi:10.1038/hr.2012.93; published online 5 July 2012

Keywords: cardiovascular disease; metabolic syndrome; olmesartan; salt intake; stroke

\section{INTRODUCTION}

Hypertension is known to be one of the main risk factors for cardiovascular disease (CVD). ${ }^{1,2}$ A number of large-scale studies on the relationship between hypertension and CVD have indicated that strict blood pressure control is important for preventing CVD. ${ }^{3,4}$

Accumulation of risk factors is related to the morbidity and mortality of CVD, so metabolic syndrome (MetS) has been attracting more attention in this context over the past decade. Diagnostic criteria for this syndrome have been published overseas, ${ }^{5,6}$ and also eight Japanese academic societies have jointly published diagnostic criteria for MetS in 2005. ${ }^{7}$ Several reports regarding the relationship between MetS and CVD in hypertensive patients have been published overseas. $^{8-10}$ In Japan, the Hisayama study ${ }^{11}$ and the Tanno and
Sobetsu study ${ }^{12}$ have provided evidence that MetS is a significant risk factor for CVD in the general population. However, no large-scale studies have been conducted in Japan to assess the risk factors for CVD in hypertensive patients who also have MetS.

The INTERSALT study ${ }^{13}$ and other studies have shown that excessive salt intake is related to high blood pressure, whereas the DASH-Sodium study ${ }^{14}$ and other large-scale studies have suggested that reducing the intake of salt is effective for lowering the blood pressure. Increased potassium intake has also been recommended for reducing the blood pressure, but there is no supportive epidemiological evidence available. Furthermore, it has been reported that intake of soy protein and omega-3 unsaturated fatty acids can be effective for preventing coronary heart disease (CHD). ${ }^{15-17}$

${ }^{1}$ Department of Internal Medicine, Teikyo University School of Medicine, Tokyo, Japan; ${ }^{2}$ Sportology Center, Juntendo University Graduate School of Medicine, Tokyo, Japan ${ }^{3}$ Department of Internal Medicine, Tokyo Teishin Hospital, Tokyo, Japan; ${ }^{4}$ Department of Clinical Trial Design and Management, Translational Research Center, Kyoto University Hospital, Kyoto, Japan and ${ }^{5}$ Daiichi Sankyo Co., Ltd, Tokyo, Japan

6See Appendix.

Correspondence: Professor T Teramoto, Department of Internal Medicine, Teikyo University School of Medicine, 2-11-1 Kaga, Itabashi-ku, Tokyo 173-8605, Japan. E-mail: ttera@med.teikyo-u.ac.jp

Received 6 February 2012; revised 24 April 2012; accepted 2 May 2012; published online 5 July 2012 
According to the Japanese Society of Hypertension Guidelines for the Management of Hypertension (JSH 2009), ${ }^{18}$ angiotensin II receptor blockers (ARBs) are positively indicated for treating hypertensive patients with various organ complications, and should be used as the first choice for patients with complications of the heart, kidneys or brain, and those with diabetes mellitus. The ARB olmesartan medoxomil (Daiichi Sankyo Co., Ltd, Tokyo, Japan) has a carboxyl group and a hydroxyl group that bind to the angiotensin 1 receptor, which is called a double-chain domain. Compared with other ARBs, olmesartan binds more strongly to the angiotensin 1 receptor and has a more potent antihypertensive effect. ${ }^{19,20}$

We conducted a large-scale prospective cohort study, the OMEGA study (olmesartan mega study to determine the relationship between cardiovascular endpoints and blood pressure goal achievement) during treatment with olmesartan medoxomil. We also investigated the relationship between blood pressure, MetS and the incidence of CVD. Furthermore, we performed a questionnaire survey to assess the intake of sodium, potassium, soybeans and fish, to investigate the relationship between dietary habits, such as salt intake and the incidence of CVD.

We have already reported the study design, baseline data ${ }^{21}$ and relationship between dietary habits and the occurrence of MetS. ${ }^{22}$

\section{METHODS}

\section{Study design}

The OMEGA study was a prospective, large-scale observational study designed to examine the relation between the incidence of CVD in Japanese hypertensive patients and the achieved blood pressure, the presence of MetS, dietary habits, such as salt intake, and other CVD risk factors. The OMEGA study was initiated in September 2005 as a post-marketing surveillance by the Sankyo Co., Ltd (presently Daiichi Sankyo Co., Ltd), in compliance with the regulations of the Japanese Ministry of Health, Labor and Welfare.

Details of the study design and the baseline clinical characteristics of the patients have been reported previously. ${ }^{21}$ Eligible patients were men or women aged 50-79 years, with physician-diagnosed hypertension, who were attending outpatient departments of the participating institutions and had not been treated with olmesartan. Exclusion criteria were a history of myocardial infarction, stroke, coronary artery bypass grafting or percutaneous coronary intervention within 6 months before enrollment, as well as scheduled coronary intervention, congenital or rheumatic heart disease, severe arrhythmia, severe hepatic or renal disease, cancer that was under treatment, and pregnancy or the potential to become pregnant. Each patient was informed of the purpose and methods of the study, as well as their right to withdraw from the study at any time and the measures taken for confidentiality. After providing written informed consent and being prescribed olmesartan, the patients were enrolled in a central electronic data capturing system. The method of blood pressure measurement was not specified, so blood pressure was measured according to the routine procedure at each institution. Data were collected before study initiation and every 6 months after initiation. We collected information on adverse events (occurrence or exacerbation of symptoms/objective findings, and other events and abnormal changes in laboratory values) recorded at each institution. This study was registered at http://www.clinicaltrials.jp/ (identification number: JapicCTI-050002). The study protocol was approved by the Ethical Committee of Sankyo Co., Ltd, and it conformed with the pharmaceutical affairs laws of Japan and was approved by the Ministry of Health, Labor and Welfare of Japan before commencement. This study conformed with the Declaration of Helsinki and was carried out at medical institutions that were registered according to Good Post-Marketing Surveillance Practice in Japan.

\section{Classification of blood pressure}

Blood pressure was classified in accordance with JSH 2009, which defines normal blood pressure as a systolic blood pressure (SBP) $<130 \mathrm{~mm} \mathrm{Hg}$ and diastolic blood pressure (DBP) $<85 \mathrm{~mm} \mathrm{Hg}$, high normal blood pressure as an SBP of $130-139 \mathrm{~mm} \mathrm{Hg}$ or DBP of $85-89 \mathrm{~mm} \mathrm{Hg}$, stage I hypertension as an SBP of $140-159 \mathrm{~mm} \mathrm{Hg}$ or DBP of $90-99 \mathrm{~mm} \mathrm{Hg}$, stage II hypertension as an SBP of $160-179 \mathrm{~mm} \mathrm{Hg}$ or DBP of $100-109 \mathrm{~mm} \mathrm{Hg}$, and stage III hypertension as an SBP $\geqslant 180 \mathrm{~mm} \mathrm{Hg}$ or DBP $\geqslant 110 \mathrm{~mm} \mathrm{Hg}$.

\section{Diagnostic criteria for MetS}

MetS was defined according to criteria established by the Japanese Society of Internal Medicine. As all of the study subjects had hypertension, one criterion for the syndrome was fulfilled at the time of enrollment. In addition, patients had to have central obesity with a waist circumference $\geqslant 85 \mathrm{~cm}$ for men or $\geqslant 90 \mathrm{~cm}$ for women, plus dyslipidemia (serum triglycerides $\geqslant 150 \mathrm{mg} \mathrm{dl}^{-1}$, or high-density lipoprotein cholesterol $<40 \mathrm{mg} \mathrm{dl}^{-1}$ ) and/or fasting hyperglycemia (plasma glucose $\geqslant 110 \mathrm{mg} \mathrm{dl}^{-1}$ ), or a diagnosis of diabetes.

\section{Diet questionnaire}

A simple questionnaire on diet was completed by the patients, which included questions on salt intake (salted fish, dried fish, fish sausage, Japanese pickles, ham/sausage, traditional Japanese and Chinese soups with a high salt content (noodle and miso soup), and use of salt and soy sauce) and on the intake of potassium (fruit) and soybeans/fish (bean curd, non-salted fermented soybeans and fish). High-salt foods were selected according to the 'Outline of the Results of the National Health and Nutrition Survey Japan, 1997.' Although both fruit and vegetables have a high content of potassium, we only assessed fruit consumption, because fruits tend to be eaten raw and retain potassium, whereas vegetables often lose potassium during cooking. The soybean foods selected were traditional Japanese dishes.

The frequency of sodium, potassium and soybean/fish intake was classified into the following 4 categories: no intake ( 1 point), eaten once or twice weekly ( 2 points), eaten 3-5 times/week (3 points) and eaten every day (4 points). For the traditional Japanese and Chinese soups, the frequency and volume of intake were investigated separately, and the intake score was calculated as the square root of the product of the frequency score and the volume score. The dietary sodium intake score was calculated as the total of the 8 intake scores and ranged from 8 to 32 points, whereas the dietary potassium intake score ranged from 1 to 4 points. The dietary soybean/fish intake score was the total of the 3 intake scores and ranged from 3 to 12 points. Lower sodium intake was defined as a score $<15.8$ points (below the 25th percentile), whereas lower intake of potassium or soybeans/fish was defined as $<2$ and $<6$ points (below the 25th percentile), respectively.

\section{Endpoints}

The endpoints were stroke (cerebral infarction, cerebral hemorrhage and subarachnoid hemorrhage), CHD (myocardial infarction and angina pectoris requiring cardiovascular intervention or hospitalization) and sudden death. CVD was defined as a composite of these three endpoints.

Stroke was diagnosed if either CT or MRI showed cerebral infarction or hemorrhage in patients who had neurological symptoms persisting for more than $24 \mathrm{~h}$ or in patients who died within $24 \mathrm{~h}$ of the onset of neurological symptoms.

Myocardial infarction was diagnosed if either the electrocardiogram or the levels of cardiac enzymes suggested infarction in patients who had symptoms consistent with acute myocardial infarction or if cardiovascular intervention was carried out to treat myocardial infarction. Stroke and myocardial infarction were not classified as fatal or non-fatal. Angina pectoris requiring cardiovascular intervention or hospitalization was diagnosed if cardiovascular intervention (including percutaneous coronary intervention or coronary bypass grafting) was performed for suspected myocardial infarction or angina pectoris, or if hospitalization was required for angina. Sudden death was defined as death within $24 \mathrm{~h}$ of the onset of symptoms that were most likely to have been associated with cerebrovascular disease/CVD, provided that there were no other possible causes.

\section{Study population size}

The target number of subjects was calculated from the assumptions shown below, to determine the risk of CVD in hypertensive patients with dyslipidemia: (1) $40 \%$ of patients with essential hypertension would have dyslipidemia, 
(2) dyslipidemia would increase the risk of CVD by 1.3-fold, and (3) the 3-year cumulative incidence of CVD in patients without dyslipidemia would be $4 \%{ }^{23,24}$ Statistical significance was set at a probability of 0.05 (two-sided) and a power $80 \%$. As a result, the number of CVD events required was 435 , and the number of subjects required was 9710 . Considering the potential for dropouts, the target number of subjects was set as 12000 .

\section{Statistical analysis}

Quantitative data are expressed as the mean \pm s.d. In evaluating the relationship between achieved blood pressure and the incidence of cardiovascular events, the Cox proportional hazards model was used with a linear contrast to test for trend of the severity of hypertension as a time-dependent covariate, adjusted by sex, age, family history of coronary artery disease, diabetes, dyslipidemia, history of CVD, body mass index and smoking. The Cox proportional hazards model was also used to investigate the relationship between dietary habits or MetS and the incidence of cardiovascular events, adjusted by baseline factors. Subgroup analyses were conducted with subjects with/without CVD history. Adverse events were coded using MedDRA/J with the preferred term for each event and the system organ class. Events for which a causal relationship with olmesartan could not be excluded were classified as adverse drug reactions, and the incidence was tabulated. Statistical analyses were conducted using SAS Release 8.2 (SAS Institute, Cary, NC, USA). All $P$-values are two-sided and those under $5 \%$ were considered statistically significant.

\section{RESULTS}

\section{Study profile and baseline characteristics}

The study was performed between July 2005 and March 2010. A total of 15313 patients were enrolled at 2219 medical institutions in Japan, and baseline data were collected from 15255 patients. Subsequently, another 534 patients were excluded because of the following reasons: 51 patients were not eligible in accordance with the protocol inclusion/exclusion criteria, 6 patients failed to take olmesartan, 244 patients had no data after the administration of olmesartan, 82 patients had no 6-month data, 63 patients withdrew consent when the 6-month follow-up was carried out and 88 patients were found to have been enrolled outside the specified enrollment period. Accordingly, a total of 14721 patients were evaluated for safety and efficacy.

The characteristics of the subjects are shown in Table 1. Their mean age was $64.9 \pm 8.2$ years and $49.6 \%$ of the patients were women. The blood pressure (SBP/DBP) at the start of olmesartan treatment was $157.4 \pm 17.7 / 88.8 \pm 12.1 \mathrm{~mm} \mathrm{Hg}$ and the pulse rate was $74.0 \pm 10.7$ beats per min. A total of 6137 patients $(41.7 \%)$ had stage I hypertension, whereas 532 patients $(3.6 \%)$ had normal blood pressure and 1040 patients $(7.1 \%)$ had high normal blood pressure at the initiation of olmesartan treatment. There were 7089 patients $(48.2 \%)$ with dyslipidemia, 3598 patients $(24.4 \%)$ with diabetes, 1780 patients (12.1\%) with liver disease and 1062 patients (7.2\%) with kidney disease. A total of 1448 patients (9.8\%) had a history of CVD, including 749 patients $(5.1 \%)$ with a history of stroke and 798 patients (5.4\%) with a history of CHD. A total of 3544 patients (24.1\%) had MetS according to the Japanese criteria. The mean follow-up period was 2.7 years.

\section{Antihypertensive treatment}

Antihypertensive treatment is shown in Table 2. The daily dose of olmesartan was $17.3 \pm 5.5 \mathrm{mg}$ at the start of the study and $17.2 \pm 8.6 \mathrm{mg}$ after 36 months of administration. The mean administration period was $922.7 \pm 391.7$ days. At the end of the study, 1725 patients $(11.7 \%)$ were not taking olmesartan.

When administration of olmesartan was started, 5784 patients (39.3\%) were already taking antihypertensive drugs, including
Table 1 Baseline characteristics of the study population

\begin{tabular}{lc}
\hline Parameter & $\mathrm{n}(\%)$ or mean $\pm s$. \\
\hline No. of patients & 14721 \\
Age (years) & $64.9 \pm 8.2$ \\
Women & $7303(49.6)$ \\
BMI $\left(\mathrm{kg} \mathrm{m}^{-2}\right)$ & $24.75 \pm 3.61$ \\
SBP $\left(\mathrm{mm} \mathrm{Hg}^{2}\right)$ & $157.4 \pm 17.7$ \\
DBP $(\mathrm{mm} \mathrm{Hg})$ & $88.8 \pm 12.1$
\end{tabular}

$74.0 \pm 10.7$

$\begin{array}{lr}\text { Severity of hypertension (JSH 2009) } & \\ \text { Normal blood pressure } & 532(3.6) \\ \text { High normal blood pressure } & 1040(7.1) \\ \text { Stage of hypertension } & \\ \text { Stage I } & 6137(41.7) \\ \text { Stage II } & 4743(32.2) \\ \text { Stage III } & 1843(12.5) \\ & \\ \text { Complications } & \\ \text { Dyslipidemia } & 7089(48.2) \\ \text { Diabetes mellitus } & 3598(24.4) \\ \text { Hepatic disease } & 1780(12.1) \\ \text { Renal disease } & 1062(7.2) \\ \text { Malignancy } & 63(0.4) \\ & \\ \text { History } & \\ \text { CVD } & 1448(9.8) \\ \text { Stroke } & 749(5.1) \\ \text { Cerebral infarction } & 600(4.1) \\ \text { Cerebral hemorrhage } & 120(0.8) \\ \text { Subarachnoid hemorrhage } & 58(0.4) \\ \text { CHD } & 798(5.4) \\ \text { Myocardial infarction } & 230(1.6) \\ \text { Cardiovascular intervention } & 301(2.0) \\ \text { Angina pectoris } & 704(4.8)\end{array}$

HDL-C (mgdl $\left.{ }^{-1}\right)$

$57.65 \pm 15.52$

LDL-C $\left(\mathrm{mgd}^{-1}\right)$

$122.77 \pm 32.57$

Triglycerides $\left(\mathrm{mgd}^{-1}\right)$

$144.48 \pm 97.35$

Fasting blood glucose $\left(\mathrm{mgd}^{-1}\right)$

$112.45 \pm 38.04$

$\begin{array}{ll}\text { Metabolic syndrome (Japanese criteria) } & \\ \text { Absent } & 7235(49.1) \\ \text { Present } & 3544(24.1) \\ \text { Unknown } & 3942(26.8) \\ & \\ \text { Smoker } & 2694(18.3) \\ \text { Alcohol drinker } & 3848(26.1) \\ \text { Antihypertensive medication } & 7090(48.2) \\ \text { Low-salt diet } & 5765(39.2) \\ \text { Dietary therapy other than low-salt diet } & 1924(13.1) \\ \text { Exercise therapy } & 3772(25.6)\end{array}$

Abbreviations: BMI, body mass index; $\mathrm{CHD}$, coronary heart disease; $\mathrm{CVD}$, cardiovascular disease; DBP, diastolic blood pressure; HDL-C, high-density lipoprotein cholesterol; LDL-C, low-density lipoprotein cholesterol; SBP, systolic blood pressure.

calcium antagonists in 4985 patients (33.9\%). At the end of the study, 7920 patients $(53.8 \%)$ were taking other antihypertensive drugs, including calcium antagonists in 6734 patients $(45.7 \%)$. At the start of the study, lipid-lowering drugs were being used by 3211 patients $(21.8 \%)$ and antidiabetic drugs were being taken by 2042 patients (13.9\%). At the end of the study, lipid-lowering drugs were 
being used by 4393 patients $(29.8 \%)$ and antidiabetic drugs were being taken by 2395 patients $(16.3 \%)$.

\section{Blood pressure and pulse rate}

The changes in the blood pressure and pulse rate are shown in Figure 1. The blood pressure (SBP/DBP) was $157.4 \pm 17.7 /$ $88.8 \pm 12.1 \mathrm{~mm} \mathrm{Hg}$ before the start of administration (baseline), and it decreased to $137.5 \pm 14.3 / 78.9 \pm 9.9 \mathrm{~mm} \mathrm{Hg}$ after 6 months of administration and to $134.0 \pm 13.2 / 76.1 \pm 9.4 \mathrm{~mm} \mathrm{Hg}$ after 36 months. Thus, the antihypertensive effect of olmesartan persisted for 36 months. The mean change in blood pressure (SBP/DBP) from baseline was $-19.5 /-9.7 \mathrm{~mm} \mathrm{Hg}$ after 6 months of administration and $-22.7 /-12.3 \mathrm{~mm} \mathrm{Hg}$ after 36 months. Both SBP and DBP were significantly reduced throughout the administration period $(P<0.0001)$. The pulse rate was $74.0 \pm 10.7$ beats per min before the start of administration, $72.5 \pm 10.0$ beats per min at 6 months after the start of administration, and $72.0 \pm 10.0$ beats per min after

Table 2 Antihypertensive treatment $(n=14721)$

\begin{tabular}{|c|c|c|c|}
\hline & Pretreatment & $\begin{array}{l}\text { Start of the } \\
\text { study }\end{array}$ & $\begin{array}{l}\text { End of the } \\
\text { study }\end{array}$ \\
\hline Olmesartan (\%) & $0(0.0)$ & $14721(100.0)$ & $12996(88.3)$ \\
\hline $\begin{array}{l}\text { Concomitant antihypertensive } \\
\text { drugs (\%) }\end{array}$ & $7558(51.8)$ & 5784 (39.3) & $7920(53.8)$ \\
\hline Calcium antagonist (\%) & $5544(37.7)$ & 4985 (33.9) & $6734(45.7)$ \\
\hline ARB (\%) & $2579(17.5)$ & $94(0.6)$ & $521(3.5)$ \\
\hline ACE inhibitor (\%) & $1057(7.2)$ & $330(2.2)$ & $358(2.4)$ \\
\hline$\beta$-blocker (\%) & 1018 (6.9) & $922(6.3)$ & $1195(8.1)$ \\
\hline Diuretic (\%) & $612(4.2)$ & $600(4.1)$ & $1432(9.7)$ \\
\hline$\alpha$-blocker (\%) & $410(2.8)$ & $350(2.4)$ & $507(3.4)$ \\
\hline $\begin{array}{l}\text { Number of antihypertensive } \\
\text { drugs }^{a} \text { (mean } \pm \text { s.d.) }\end{array}$ & $0.8 \pm 0.9$ & $1.5 \pm 0.7$ & $1.6 \pm 0.9$ \\
\hline
\end{tabular}

Abbreviations: ACE, angiotensin-converting enzyme; ARB, angiotensin receptor blocker aOlmesartan is included except for pretreatment.

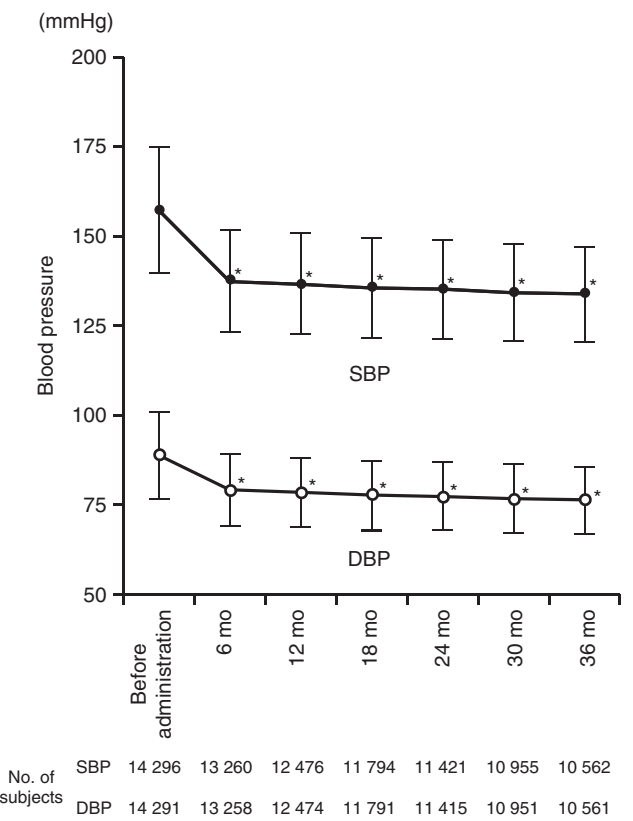

36 months. Therefore, the reduction of the pulse rate by olmesartan persisted for 36 months $(P<0.0001)$

When changes in the blood pressure and pulse rate were compared in patients with MetS with patients without MetS, the baseline blood pressure (SBP/DBP) was $157.4 \pm 17.2 / 89.2 \pm 12.1$ and $158.7 \pm 17.6 /$ $89.5 \pm 11.9 \mathrm{~mm} \mathrm{Hg}$ in patients with and without MetS, respectively. After 6 months of olmesartan treatment, the blood pressure (SBP/ DBP) was $139.2 \pm 14.3 / 80.0 \pm 10.0$ and $136.7 \pm 13.6 / 78.7 \pm 9.5 \mathrm{~mm} \mathrm{Hg}$ in patients with and without MetS, respectively, whereas the respective values after 12, 18, 24, 30 and 36 months were 138.4 \pm 14.6/79.2 \pm 9.6 , $137.4 \pm 14.1 / 78.5 \pm 9.6,137.2 \pm 14.3 / 78.0 \pm 9.6,136.2 \pm 14.0 / 77.4 \pm 9.7$, $135.4 \pm 13.0 / 76.8 \pm 9.4 \mathrm{mmHg}$ in patients with MetS, respectively and $136.2 \pm 13.6 / 78.1 \pm 9.3,135.1 \pm 13.3 / 77.3 \pm 9.4,134.3 \pm 13.2 / 76.9 \pm 9.3$, $133.8 \pm 13.1 / 76.5 \pm 9.2, \quad 133.4 \pm 13.0 / 76.1 \pm 9.3 \mathrm{mmHg}$ in patients without MetS, respectively. Accordingly, a significant antihypertensive effect of olmesartan persisted for all measurement timing in both patient populations $(P<0.0001)$. The baseline pulse rate was $74.5 \pm 11.0$ and $73.6 \pm 10.3$ beats per $\min$ in patients with and without MetS, respectively. After 6 months, the pulse rate was $73.4 \pm 10.3$ and $71.9 \pm 9.4$ beats per min in patients with and without MetS, respectively, whereas the respective values after 12, 18, 24, 30 and 36 months were $73.0 \pm 10.5,72.9 \pm 10.5,72.9 \pm 10.5,72.7 \pm 10.4$, $72.8 \pm 10.3$ beats per min in patients with MetS, respectively and $71.8 \pm 9.6,71.9 \pm 9.5,71.7 \pm 9.8,71.6 \pm 9.6,71.5 \pm 9.6$ beats per min in patients without MetS, respectively. Therefore, the reduction of the pulse rate by olmesartan persisted for all measurement timing $(P<0.0001)$. Both SBP and DBP were approximately $2 \mathrm{~mm} \mathrm{Hg}$ lower in the patients without MetS than in those with MetS, and the pulse rate was also lower in patients without MetS.

\section{CVD events and incidence of CVD}

The number of CVD events and the incidence of CVD (per 1000 persons annually) are shown in Table 3. All of the CVD events that are recorded in the Table fitted the diagnostic criteria mentioned earlier. The estimated incidence of CVD, stroke and CHD was 7.15, 3.42 and 3.55 , respectively (per 1000 persons annually).

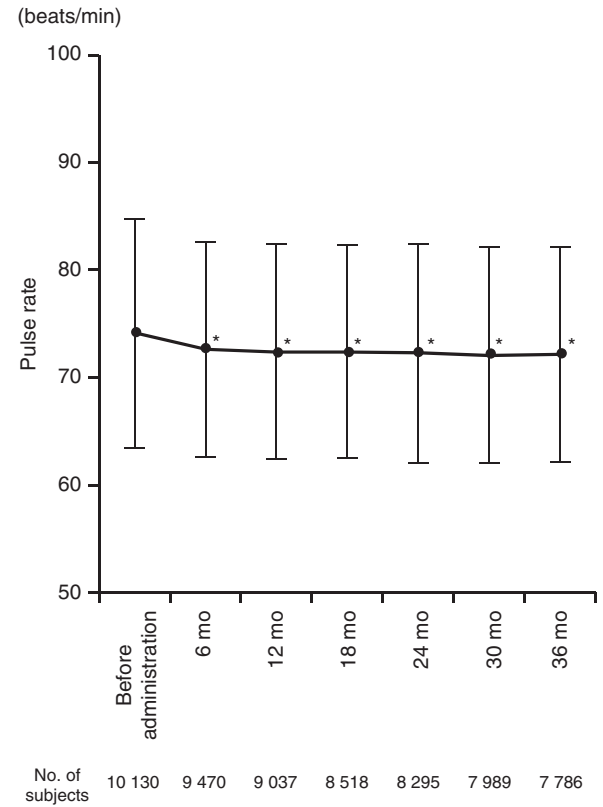

Figure 1 Changes of blood pressure and pulse rate during administration of olmesartan. Abbreviations: DBP, diastolic blood pressure; SBP, systolic blood pressure. ${ }^{*} P<0.01$, Dunnett-Hsu test. 
Table 3 Number of patients and incidence of CVD and events in 14721 patients

\begin{tabular}{lrc}
\hline CVD & $\begin{array}{c}\text { Number } \\
\text { of events }\end{array}$ & $\begin{array}{c}\text { Incidence } \\
(95 \% \mathrm{Cl})\end{array}$ \\
\hline Stroke & 281 & $7.15(6.36,8.04)$ \\
$\quad$ Cerebral infarction & 135 & $3.42(2.89,4.05)$ \\
Cerebral hemorrhage & 110 & $2.78(2.31,3.36)$ \\
Subarachnoid hemorrhage & 20 & $0.50(0.33,0.78)$ \\
CHD & 6 & $0.15(0.07,0.34)$ \\
Myocardial infarction & 140 & $3.55(3.01,4.19)$ \\
Cardiovascular intervention for angina pectoris & 38 & $0.96(0.70,1.32)$ \\
$\quad$ Hospitalization due to angina pectoris other & 25 & $2.08(1.67,2.58)$ \\
than cardiovascular intervention & &
\end{tabular}

Sudden death

$14 \quad 0.35(0.21,0.60)$

Abbreviations: $\mathrm{CHD}$, coronary heart disease; $\mathrm{Cl}$, confidence interval; CVD, cardiovascular disease.

The estimated incidence of cerebral infarction and angina pectoris requiring cardiovascular intervention was 2.78 and 2.08 , respectively (per 1000 persons annually).

\section{Relation between blood pressure and CVD in all subjects}

The findings with regard to CVD, stroke and CHD in all subjects are shown in Figure 2a.

There was a significant relationship between the blood pressure and the occurrence of CVD or stroke. The risk of CVD and the risk of stroke both increased along with the severity of hypertension $(P<0.0001$ for trend analysis), but the risk of stroke showed a greater increase than that of CVD. The hazards ratio (HR) for CVD and stroke in patients with stage III hypertension was 5.185 (95\% confidence interval (CI), 3.013-8.921) and 8.952 (95\% CI, 4.273-18.755), respectively.

Unlike CVD and stroke, the risk of CHD did not increase along with the severity of hypertension ( $P=0.0787$ for trend analysis), although it was significantly higher in patients with stage III hypertension (HR, 2.514; 95\% CI, 1.043-6.063).

\section{Analysis of patients without a history of CVD}

The risk of CVD, stroke and CHD in the patients without a history of CVD is shown in Figure $2 b$.

In this subgroup, the relationship between blood pressure and the occurrence of CVD was more obvious compared with that in all subjects. There was a significant relationship between the blood pressure and the occurrence of CVD or stroke, as was noted in all subjects.

The risk of CVD and stroke also increased along with the severity of hypertension $(P<0.0001$ for trend analysis $)$, and the HRs were highest for patients with stage III hypertension, being 6.088 (95\% CI, 3.200-11.583) for CVD and 12.140 (95\% CI, 4.895-30.108) for stroke.

As was found in all subjects, the risk of CHD did not increase along with the severity of hypertension ( $P=0.1055$ for trend analysis), but it was significantly higher for patients with stage III hypertension (HR, 3.089; 95\% CI, 1.146-8.326).

\section{Relation between MetS and CVD}

The incidence of cardiovascular events in patients with or without MetS is shown in Table 4. The incidence of CVD, stroke and CHD was higher in the patients with MetS than in the patients without MetS, but the differences were not significant in all subjects. However, the incidence of stroke was significantly higher in female patients with MetS than in female patients without MetS (HR, 2.590; 95\% CI, $1.190-5.638)$.

\section{Relation between dietary habits and CVD}

The relation between dietary habits and events is summarized in Figure 3. The risk of CVD in relation to salt intake was investigated by classifying the subjects into two groups based on their scores for salt intake $(<15.8$ (lowest quartile) and $\geqslant 15.8$ ). The risk of stroke was significantly higher in the higher intake group than in the lower intake group (HR, 1.897; 95\% CI, 1.003-3.590), but the risk of CVD and CHD did not significantly differ between the two groups. We also observed a lower stroke risk in the higher potassium intake and higher soybean/fish intake groups compared with the respective lower intake groups, but no significant differences were noted for stroke or for other endpoints.

\section{Safety}

The incidence of adverse drug reactions in all subjects was $4.41 \%$ $(649 / 14721)$. The common adverse drug reactions included dizziness (0.56\%, 82 episodes), hyperkalemia $(0.46 \%, 67$ episodes), decreased blood pressure $(0.22 \%, 32$ episodes), hypotension $(0.21 \%, 31$ episodes) and hepatic impairment $(0.20 \%, 29$ episodes). The incidence of adverse drug reactions within 6 months after starting administration of olmesartan was $2.27 \%$ (334/14 721). Most adverse reactions occurred within 6 months of starting treatment, and the incidence of adverse reactions declined as the duration of olmesartan administration was prolonged.

\section{DISCUSSION}

In the present study, the annual incidence of CVD per 1000 persons was 7.15, and the HRs for CVD, stroke and CHD increased along with the severity of hypertension (classified in accordance with JSH 2009). This trend was most obvious with regard to the risk of stroke. In addition, the risk of stroke differed significantly between female patients with and without MetS. There was also a relationship between dietary habits and the risk of stroke, as the HR for stroke was significantly lower in subjects with a lower salt intake than in those with a higher salt intake.

On the basis of the results of previous studies, ${ }^{23-25}$ we planned to investigate 9710 patients with an estimated 435 CVD events, but actually investigated 14721 patients with $281 \mathrm{CVD}$ events, so the number of events was lower than expected. There was no control group in this study, so we tried to compare our outcomes with the results of a similar cohort study. A study of the ARB telmisartan was conducted at approximately the same time with a similar objective, design, target patient population, number of subjects, definition of CVD and achieved blood pressure (J-TARGET study). ${ }^{26}$ In that study, the annual incidence of CVD, stroke, CHD and sudden death per 1000 patients was $11.0,5.0,5.5$ and 0.7 , respectively, whereas in this study, the annual incidence was $7.15,3.42,3.55$ and 0.35 , respectively. Although direct comparison between the two studies is somewhat problematic, the incidence of events was lower in hypertensive patients receiving olmesartan therapy. The following three factors might have contributed to the lower incidence of events in this study in comparison with previous studies and a recent similar cohort study. First, recent hypertension treatment guidelines ${ }^{18,27}$ released after earlier studies ${ }^{23-24}$ have promoted stricter blood pressure 
Normal BP: $\mathrm{SBP}<130$ and $\mathrm{DBP}<85$
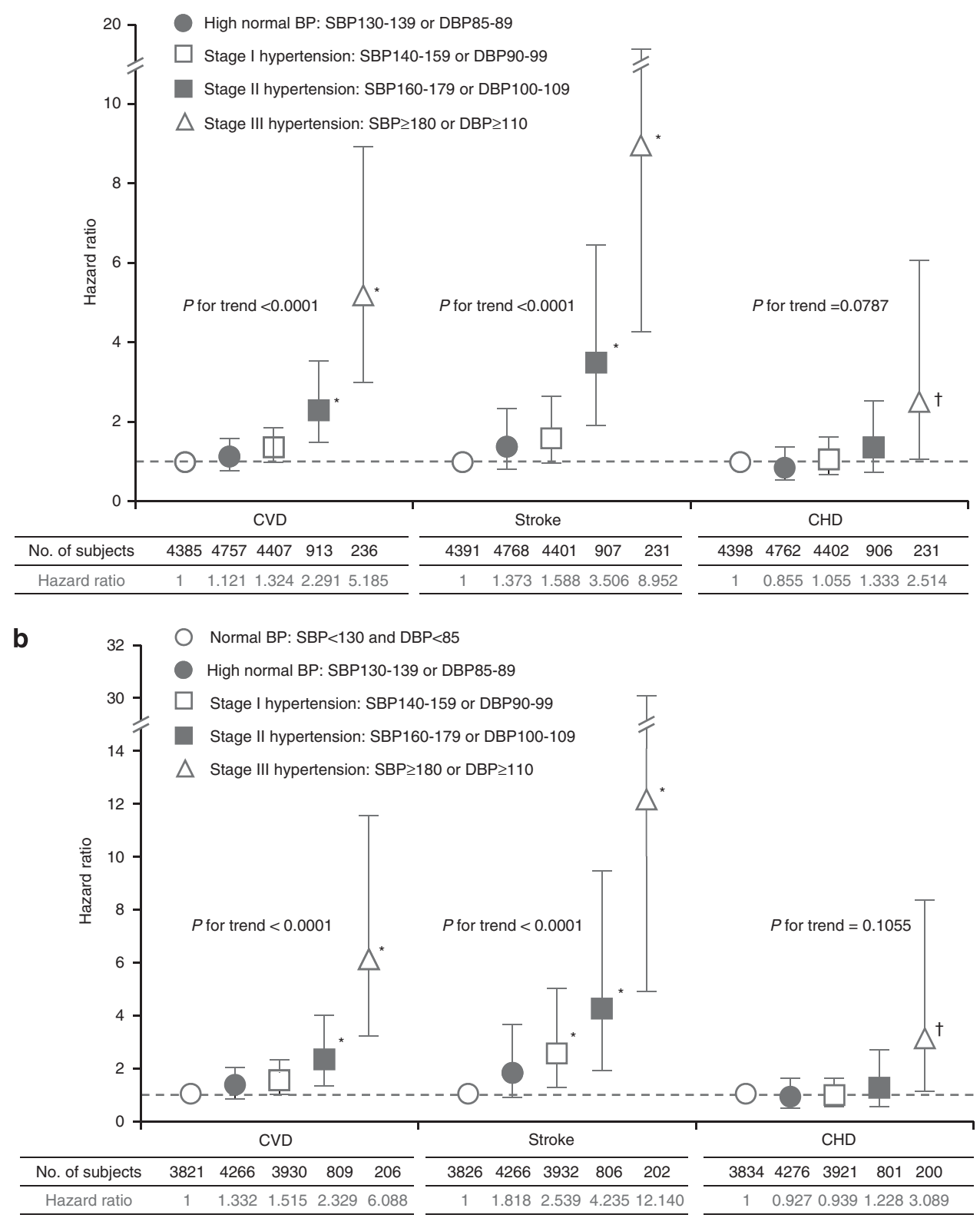

Figure 2 Relationship between the achieved blood pressure and occurrence of events during follow-up in all subjects (a) and in the patients without a history of CVD (b). Vertical lines denote $95 \%$ Cls. Cox proportional hazards model: Adjusted by sex, age, family history of coronary artery disease, diabetes, dyslipidemia, history of CVD, BMI and smoking. Number of subjects of each categories were shown as the counted number, based on the blood pressure of at final visit point or at last visit point before the event occurs. ${ }^{\dagger} P<0.05,{ }^{*} P<0.01$ vs. normal BP. BMI, body mass index; $\mathrm{CHD}$, coronary heart disease; $\mathrm{Cl}$, confidence interval; CVD, cardiovascular disease; DBP, diastolic blood pressure; SBP, systolic blood pressure.

control, and progress in antihypertensive medications has led to the widespread use of ARBs as first-line therapy for the majority of patients receiving aggressive treatment. Second, progress in the general medical environment and in the treatment of other diseases, such as dyslipidemia, may have contributed to a better outcome. ${ }^{28}$ Third, the more potent antihypertensive effect and longer duration of action of olmesartan, ${ }^{29-31}$ as well as its pleiotropic effects, ${ }^{32,33}$ could have had a favorable influence.

Staessen et $a l .{ }^{34}$ performed a meta-analysis and concluded that antihypertensive therapy was necessary for the prevention of CVD, and that the antihypertensive effect of drug therapy influenced the risk of CVD. ${ }^{35}$ In addition, the results of the HOT study suggest that the blood pressure should be maintained below 140/90 $\mathrm{mm} \mathrm{Hg}$ for prevention of CVD. ${ }^{3}$ In our study, the trends of CVD and stoke were more apparent when the achieved SBP and DBP were combined rather than being assessed separately. We classified blood pressure levels in accordance with JSH 2009, and we did not identify a J-curve in any group, unlike reports from overseas. ${ }^{36}$ In fact, our findings suggest that it is important to at least achieve a normal blood pressure (SBP $<130 \mathrm{~mm} \mathrm{Hg}$ and DBP $<85 \mathrm{~mm} \mathrm{Hg}$ ) and that the combined target blood pressure for SBP/DBP recommended by JSH 2009 is reasonable. In the present study, patients with a history of CVD comprised $10 \%$ of all subjects. In patients without a history of CVD, the increase in the risk of CVD along with the severity of hypertension 
was more obvious. This was probably because the power of our study was insufficient owing to the small number of CVD events among patients with a history of CVD, as well as because a history of CVD is a risk factor for future CVD, and because of the influence of other risk factors, including dyslipidemia. In the present study, the risk of CHD did not show a significant increase along with the severity of hypertension, suggesting that $\mathrm{CHD}$ is less strongly influenced by hypertension compared with stroke. However, the risk of $\mathrm{CHD}$ was still increased in patients with severe hypertension (stage III according

Table 4 The incidence of CVD event according to the presence or absence of MetS (Japanese criteria)

\begin{tabular}{|c|c|c|c|c|}
\hline & \multicolumn{2}{|c|}{ Incidence ( per 1000 person-years) } & \multirow[b]{2}{*}{$H R(95 \% \mathrm{Cl})$} & \multirow[b]{2}{*}{ P-value } \\
\hline & Mets (-) & MetS $(+)$ & & \\
\hline \multicolumn{5}{|l|}{ Total } \\
\hline CVD & 5.05 & 8.13 & $1.317(0.944,1.837)$ & 0.1047 \\
\hline Stroke & 2.57 & 3.92 & $1.240(0.772,1.990)$ & 0.3732 \\
\hline $\mathrm{CHD}$ & 2.46 & 3.92 & $1.248(0.776,2.006)$ & 0.3608 \\
\hline \multicolumn{5}{|l|}{ Men } \\
\hline CVD & 7.80 & 8.96 & $1.162(0.787,1.716)$ & 0.4503 \\
\hline Stroke & 4.26 & 3.83 & $0.885(0.505,1.549)$ & 0.6678 \\
\hline $\mathrm{CHD}$ & 3.80 & 4.90 & $1.347(0.784,2.315)$ & 0.2806 \\
\hline \multicolumn{5}{|l|}{ Women } \\
\hline CVD & 3.46 & 6.17 & $1.742(0.958,3.168)$ & 0.0687 \\
\hline Stroke & 1.59 & 4.11 & $2.590(1.190,5.638)$ & 0.0165 \\
\hline $\mathrm{CHD}$ & 1.68 & 1.64 & $0.916(0.311,2.698)$ & 0.8739 \\
\hline
\end{tabular}

Abbreviations: $\mathrm{CHD}$, coronary heart disease; $\mathrm{Cl}$, confidence interval; $\mathrm{CVD}$, cardiovascula disease; HR, hazard ratio; MetS, metabolic syndrome. to JSH 2009). We plan to report the results of a detailed assessment of risk factors in the future.

In JSH 2009, either ARBs or angiotensin-converting enzyme inhibitors are recommended as first-line therapy for hypertension in patients with MetS, because these drugs can improve insulin resistance. ${ }^{7}$ It has been reported that olmesartan improves insulin resistance by increasing cyclic adenosine monophosphate and decreasing tumor necrosis factor- $\alpha^{37}$ In the present study, the final blood pressure was $135.4 / 76.8$ and $133.4 / 76.1 \mathrm{~mm} \mathrm{Hg}$ for patients with and without MetS, respectively, so olmesartan showed a good antihypertensive effect regardless of whether patients had MetS.

The Hisayama study showed that the risk of CVD is significantly higher in hypertensive patients with MetS than in those without MetS, ${ }^{12}$ but we found no significant difference with regard to the risk of CVD in the present study. This discrepancy was considered to have occurred because our study population consisted entirely of hypertensive patients, so that hypertension might be more closely associated with CVD than with other factors among MetS components, although the blood pressure of our MetS patients was reduced to almost the same level as that of the patients without MetS, and the difference of blood pressure between our subjects with and without MetS was very small. We also investigated the influence of gender in relation to MetS and found that the incidence of stroke was significantly higher in female patients with MetS than in female patients without MetS. We interpret the reason why the presence or absence of MetS influenced on the difference of stroke outcomes as that, in general, women associated with the fewer environmental risks, such as smoking (current smoking rate; men, 30.9\%, women, $6.7 \%$ ).

A meta-analysis of the results of 19 cohort studies suggested that the incidence of CVD, especially stroke, is higher in people with a high salt intake. ${ }^{38}$ In the United States, the Third National Health and Nutrition Examination Survey revealed a higher mortality rate in

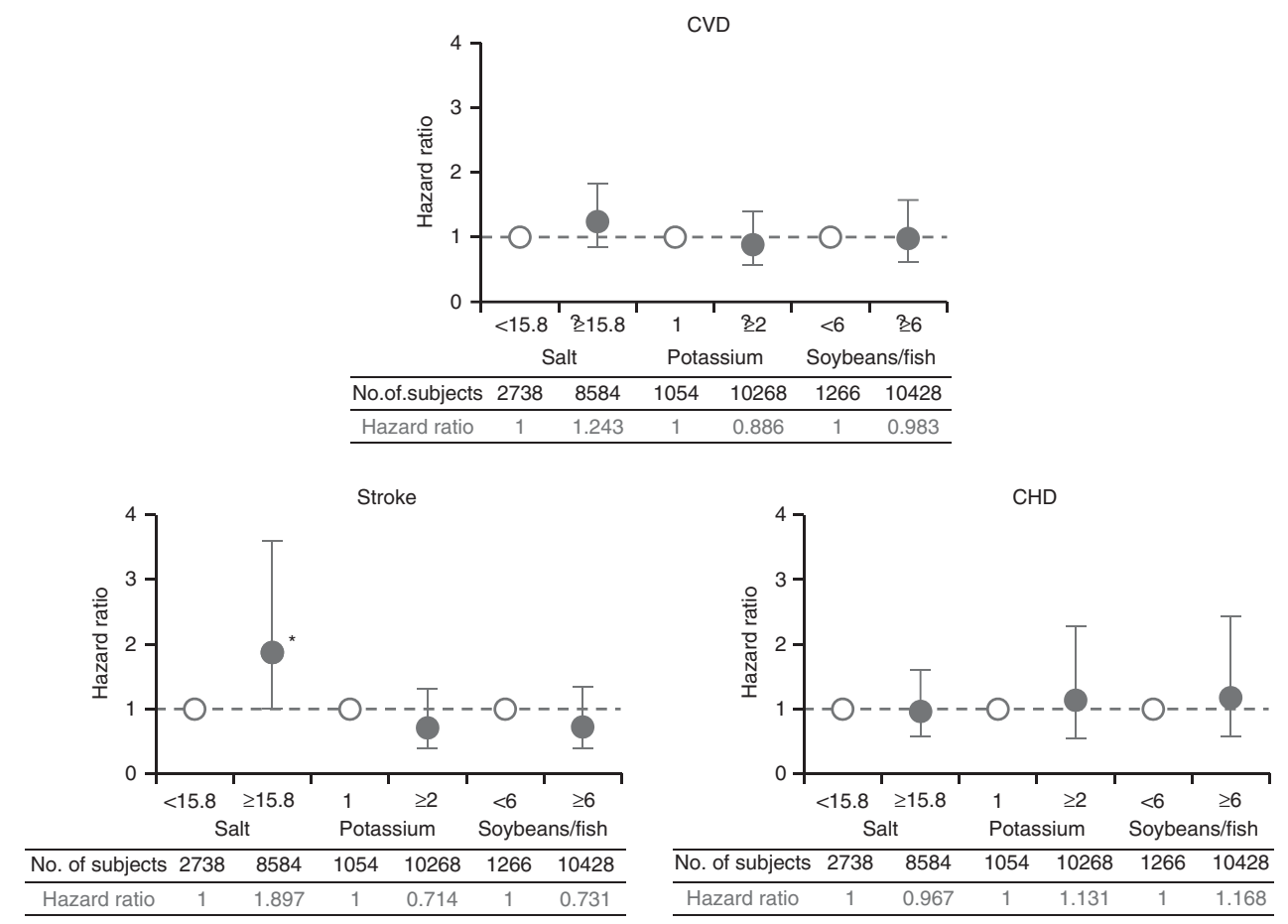

Figure 3 Relationship between dietary habits (food scores) and events. Vertical lines denote 95\% Cls. Cox proportional hazards model: adjusted by sex, age, baseline blood pressure, family history of coronary artery disease, diabetes mellitus, dyslipidemia and smoking. ${ }^{*} P<0.05$. CHD, coronary heart disease; $\mathrm{Cl}$, confidence interval; CVD, cardiovascular disease. 
people with a high sodium intake. ${ }^{39}$ We classified the patients by their salt intake scores at lowest quartile $(<15.8$ and $\geqslant 15.8)$ and found that the risk of stroke was significantly higher in the higher salt intake group than in the lower salt intake group. The salt intake score was significantly related to the risk of stroke, probably because hypertension due to excessive salt intake is one of the main risk factors for stroke. According to the equation of Arakawa et al. ${ }^{40}$ a salt intake score of 15.8 is equivalent to $9 \mathrm{~g}$ of salt daily for men and $6 \mathrm{~g}$ for women.

In the present study, potassium intake had no significant influence on blood pressure, possibly because potassium does not affect blood pressure as much as sodium. It is also possible that there were not enough items related to potassium intake in the questionnaire that we used. However, a combination of foods with a weak antihypertensive effect might show a stronger antihypertensive effect, so high intake of vegetables, fruits and fish, along with limited intake of cholesterol and saturated fatty acids may be important for the management of hypertension.

This study had several limitations. As there was no control group, we could not evaluate the effectiveness of olmesartan medoxomil itself. Also, subjects were only asked about MetS and their dietary habits at the start of the study rather than throughout the study period.

In conclusion, the severity of hypertension (achieved blood pressure) is associated with the incidence of CVD, and the results of this study suggest that tight blood pressure control and salt restriction are important for preventing stroke.

\section{CONFLICT OF INTEREST}

MS, KH and FK are employees of Daiichi Sankyo Co., Ltd.

\section{ACKNOWLEDGEMENTS}

We are grateful to all the patients, physicians and medical staff who participated in the OMEGA study. Financial support for this study was provided by Daiichi Sankyo, Co., Ltd (Tokyo, Japan).

1 Kannel WB. Blood pressure as a cardiovascular risk factor: prevention and treatment. JAMA 1996; 275: 1571-1576.

2 Lawes CM, Rodgers A, Bennett DA, Parag V, Suh I, Ueshima H, MacMahon S. Asia Pacific Cohort Studies Collaboration. Blood pressure and cardiovascular disease in the Asia Pacific region. J Hypertens 2003; 21: 707-716.

3 Hansson L, Zanchetti A, Carruthers SG, Dahlöf B, Elmfeldt D, Julius S, Ménard J, Rahn $\mathrm{KH}$, Wedel $\mathrm{H}$, Westerling S. Effects of intensive blood pressure lowering and low-dose aspirin in patients with hypertension: principal results of the Hypertension Optimal Treatment (HOT) randomized trial. HOT Study Group. Lancet 1998; 351: 1755-1762.

4 Liu L, Zhang Y, Liu G, Li W, Zhang X, Zanchetti A. FEVER Study Group. The Felodipine Event Reduction (FEVER) Study: a randomized long-term placebo-controlled trial in Chinese hypertensive patients. J Hypertens 2005; 23: 2157-2172.

5 Expert Panel on Detection, Evaluation, And Treatment of High Blood Cholesterol In Adults. Executive Summary of the Third Report of the National Cholesterol Education Program (NCEP) Expert Panel on Detection, Evaluation, And Treatment of High Blood Cholesterol In Adults (Adult Treatment Panel III). JAMA 2001: 285: 2486-2497.

6 Grundy SM, Cleeman JI, Daniels SR, Donato KA, Eckel RH, Franklin BA, Gordon DJ, Krauss RM, Savage PJ, Smith Jr SC, Spertus JA, Costa F. American Heart Association; National Heart, Lung, and Blood Institute. American Heart Association; National Heart, Lung, and Blood Institute. Diagnosis and Management of the Metabolic Syndrome: an American Heart Association/National Heart, Lung, and Blood Institute Scientific Statement. Circulation 2005; 112: 2735-2752.

7 The Committee of Establishing the Definition of the Diagnosis of Metabolic Syndrome in Japan: The definition of the diagnosis of metabolic syndrome in Japan. J Jpn Soc Int Med 2005; 94: 188-203. In Japanese.

8 Dekker JM, Girman C, Rhodes T, Nijpels G, Stehouwer CD, Bouter LM, Heine RJ. Metabolic syndrome and 10-year cardiovascular disease risk in the Hoorn Study. Circulation 2005; 112: 666-673

9 McNeill AM, Rosamond WD, Girman CJ, Golden SH, Schmidt MI, East HE, Ballantyne CM, Heiss G. The metabolic syndrome and 11-year risk of incident cardiovascular disease in the Atherosclerosis Risk in Communities Study. Diabetes Care 2005; 28: 385-390.
10 Scuteri A, Najjar SS, Morrell CH, Lakatta EG. Cardiovascular Health Study. The metabolic syndrome in older individuals: prevalence and prediction of cardiovascular events: the Cardiovascular Health Study. Diabetes Care 2005; 28: 882-887.

11 Ninomiya T, Kubo M, Doi Y, Yonemoto K, Tanizaki Y, Rahman M, Arima H, Tsuryuya K, lida M, Kiyohara Y. Impact of metabolic syndrome on the development of cardiovascular disease in a general Japanese population: the Hisayama study. Stroke 2007; 38: 2063-2069.

12 Takeuchi H, Saitoh S, Takagi S, Ohnishi H, Ohhata J, Isobe T, Shimamoto K. Metabolic syndrome and cardiac disease in Japanese men: applicability of the concept of metabolic syndrome defined by the National Cholesterol Education Program-Adult Treatment Panel III to Japanese men-the Tanno and Sobetsu Study. Hypertens Res 2005; 28: 203-208.

13 Intersalt Cooperative Research Group. Intersalt: an international study of electrolyte excretion and blood pressure. Results for 24 hour urinary sodium and potassium excretion. BMJ 1988; 297: 319-328.

14 Sacks FM, Svetkey LP, Vollmer WM, Appel LJ, Bray GA, Harsha D, Obarzanek E, Conlin PR, Miller 3rd ER, Simons-Morton DG, Karanja N, Lin PH. DASH-Sodium Collaborative Research Group. Effects on blood pressure of reduced dietary sodium and the Dietary Approaches to Stop Hypertension (DASH) diet. DASH-Sodium Collaborative Research Group. N Engl J Med 2001; 344: 3-10.

15 GISSI-Prevenzione investigators. Dietary supplementation with n-3 polyunsaturated fatty acids and vitamin E after myocardial infarction: results of the GISSI-Prevenzione trial. Lancet 1999; 354: 447-455.

16 Bucher HC, Hengstler P, Schindler C, Meier G. N-3 polyunsaturated fatty acids in coronary heart disease: a meta-analysis of randomized controlled trials. Am J Med 2002; 112: 298-304.

17 Anderson JW, Johnstone BM, Cook-Newell ME. Meta-analysis of the effects of soy protein intake on serum lipids. N Engl J Med 1995; 333: 276-282.

18 Ogihara T, Kikuchi K, Matsuoka H, Fujita T, Higaki J, Horiuchi M, Imai Y, Imaizumi T, Ito S, Iwao H, Kario K, Kawano Y, Kim-Mitsuyama S, Kimura G, Matsubara H, Matsuura H, Naruse M, Saito I, Shimada K, Shimamoto K, Suzuki H, Takishita S, Tanahashi N, Tsuchihashi T, Uchiyama M, Ueda S, Ueshima H, Umemura S, Ishimitsu T, Rakugi $\mathrm{H}$. On behalf of The Japanese Society of Hypertension Committee. Japanese society of hypertension committee: the Japanese society of hypertension guidelines for the management of hypertension (JSH 2009). Hypertens Res 2009; 32: 3-107.

19 Koike H, Konse T, Sada T. Olmesartan medoxomil, a novel potent angiotensin II blocker. Ann Rep Sankyo Lab 2003; 55: 1-91.

20 Miura S, Fujino M, Saku K. Angiotensin II receptor blocker as an inverse agonist: A current perspective. Curr Hypertens Rev 2005; 1: 115-121.

21 Teramoto T, Fujita T, Kawamori R, Miyazaki S, Teramukai S, Igarashi M. OMEGA study: design, baseline data, metabolic syndrome prevalence in a large-scale observational study of hypertensive patients: the Olmesartan Mega Study to Determine the Relationship Between Cardiovascular Endpoints and Blood Pressure Goal Achievement Study. Hypertens Res 2008; 31: 2011-2017.

22 Teramoto T, Kawamori R, Miyazaki S, Teramukai S. OMEGA Study Group. Sodium intake in men and potassium intake in women determine the prevalence of metabolic syndrome in Japanese hypertensive patients: OMEGA Study. Hypertens Res 2011; 34: 957-962.

23 Kinjo K, Kimura Y, Shinzato Y, Tomori M, Komine Y, Kawazoe N, Takishita S, Fukiyama K, COSMO Group. An epidemiological analysis of cardiovascular disease in Okinawa, Japan. Hypertens Res 1992; 15: 111-119.

24 The GLANT Study Group. A 12-month comparison of ACE inhibitor and CA antagonist therapy in mild to moderate essential hypertension-The GLANT Study. Study Group on Long-term Antihypertensive Therapy. Hypertens Res 1995; 18: 235-244.

25 Hashikata H, Harada K, Kagimura T, Nakamura M, Koizumi A. Usefulness of a large automated health records database in pharmacoepidemiology. Environ Health Prev Med 2011; 16: 313-319.

26 Komuro I, Kawamori R, Teramoto T, Kagimura T, Koizumi A. Japanese telmisartan study for antihypertensive good effect in long-term observation (J-target). J Blood Press 2011; 18: 1010-1021. In Japanese.

27 Japanese Society of Hypertension. Japanese society hypertension guidelines for the management of hypertension (JSH 2004). Hypertens Res 2006; 29: S1-105.

28 Japan Atherosclerosis Society Guidelines for Prevention of Atherosclerotic Cardiovascular Diseases. Kyowa Kikaku, Tokyo, 2007, In Japanese.

29 Oparil S, Williams D, Chrysant SG, Marbury TC, Neutel J. Comparative efficacy of olmesartan, losartan, valsartan, and irbesartan in the control of essential hypertension. J Clin Hypertens (Greenwich) 2001; 3: 283-291.

30 Brunner HR, Stumpe KO, Januszewicz A. Antihypertensive efficacy of olmesartan medoxomil and candesartan cilexetil assessed by 24-hour ambulatory blood pressure monitoring in patients with essential hypertension. Clin Drug Investig 2003; 23: 419-430.

31 Smith DH, Dubiel R, Jones M. Use of 24-hour ambulatory blood pressure monitoring to assess antihypertensive efficacy: a comparison of olmesartan medoxomil, losartan potassium, valsartan, and irbesartan. Am J Cardiovasc Drugs 2005; 5: 41-50.

32 Hirohata A, Yamamoto K, Miyoshi T, Hatanaka K, Hirohata S, Yamawaki H, Komatsubara I, Murakami M, Hirose E, Sato S, Ohkawa K, Ishizawa M, Yamaji H, Kawamura H, Kusachi $\mathrm{S}$, Murakami T, Hina K, Ohe T. Impact of olmesartan on progression of coronary atherosclerosis: a serial volumetric intravascular ultrasound analysis from the OLIVUS (impact of olmesartan on progression of coronary atherosclerosis: evaluation by intravascular ultrasound) trial. J Am Coll Cardiol 2010; 55: 976-982.

33 Fliser D, Buchholz K, Haller HEUropean Trial on Olmesartan and Pravastatin in Inflammation and Atherosclerosis (EUTOPIA) Investigators. Antiinflammatory effects of 
angiotensin II subtype 1 receptor blockade in hypertensive patients with microinflammation. Circulation 2004; 110: 1103-1107.

34 Staessen JA, Wang JG, Thijs L. Cardiovascular protection and blood pressure reduction: a meta-analysis. Lancet 2001; 358: 1305-1315.

35 Staessen JA, Gasowski J, Wang JG, Thijs L, Den Hond E, Boissel JP, Coope J, Ekbom T, Gueyffier F, Liu L, Kerlikowske K, Pocock S, Fagard RH. Risks of untreated and treated isolated systolic hypertension in the elderly: meta-analysis of outcome trials. Lancet 2000; 355: 865-872.

36 Cooper-DeHoff RM, Gong Y, Handberg EM, Bavry AA, Denardo SJ, Bakris GL, Pepine CJ. Tight blood pressure control and cardiovascular outcomes among hypertensive patients with diabetes and coronary artery disease. JAMA 2010; 304: 61-68.

37 Yamaguchi K, Ura N, Murakami H, Togashi N, Hyakukoku M, Higashiura K, Shimamoto $\mathrm{K}$. Olmesartan ameliorates insulin sensitivity by modulating tumor necrosis factoralpha and cyclic AMP in skeletal muscle. Hypertens Res 2005; 28: 773-778.

$38 \mathrm{He}$ FJ, MacGregor GA. Effect of longer-term modest salt reduction on blood pressure. Cochrane Database Syst Rev 2004: 3. CD004937.
39 Yang Q, Liu T, Kuklina EV, Flanders WD, Hong Y, Gillespie C, Chang MH, Gwinn M, Dowling N, Khoury MJ, Hu FB. Sodium and potassium intake and mortality among US adults: prospective data from the Third National Health and Nutrition Examination Survey. Arch Intern Med 2011; 171: 1183-1191.

40 Arakawa K, Matsushita Y, Matsuo H, Ikeda N, Iwashita M, Kuramoto K. Examination of the efficiency of salt taste preference questionnaire in hypertensive patients-results from post marketing surveillance of Olmetec ${ }^{\circledR}$ tablets and Calblock ${ }^{\circledR}$ tablets. J Clin Ther Med 2009; 25: 723-734. In Japanese.

This work is licensed under the Creative Commons Attribution-NonCommercial-No Derivative Works 3.0 Unported License. To view a copy of this license, visit http:// creativecommons.org/licenses/by-nc-nd/3.0/

Supplementary Information accompanies the paper on Hypertension Research website (http://www.nature.com/hr)

\section{APPENDIX}

OMEGA Study Medical Expert Advisory Committee

Medical Advisors: Toshiro Fujita, Ryuzo Kawamori, Shigeru

Miyazaki and Tamio Teramoto.

Statistical Advisor: Satoshi Teramukai. 